\title{
1 Selection of rainfall information as input data for the design of combined sewer overflow
}

2 solutions

3 Marie-Ève Jean*

4 marie-eve.jean@ete.inrs.ca, Eau Terre Environnement Research Centre, Institut National de

5 la recherche scientifique, 490 Couronne St, Québec, Canada, G1K 9A9

6 Sophie Duchesne

7 sophie.duchesne@ete.inrs.ca, Eau Terre Environnement Research Centre, Institut National de

8 la recherche scientifique, Québec, Canada

9 Geneviève Pelletier

10 Genevieve.Pelletier@gci.ulaval.ca, Department of Civil and Water Engineering, Laval

11 University, Québec, Canada,

12 Martin Pleau

13 Martin.Pleau@tetratech.com, Tetra Tech CSO, Québec, Canada,

$14 *$ Corresponding author

15 Declarations of interest: none

16 Abstract

17 Combined sewer overflows (CSOs) cause environmental problems and health risks, but poor 18 guidance exists on the use of rainfall data for sizing optimal CSO control solutions. This

19 study first reviews available types of rainfall information as input for CSO modelling and,

20 secondly, assesses the impacts of three rainfall data selection methods (continuous simulation,

21 historical rainstorms selected based on rainfall depth or maximum intensity and IDF-derived

22 storms) on the estimation of CSO volume thresholds to control in order to reach specific

23 seasonal CSO frequency targets. The methodology involves hydrological/hydraulic modelling

24 of an urban catchment in the Province of Québec (Canada). Continuous simulation provides

25 the most accurate volume estimations and shows high sensitivity to the number of simulated 
years. Alternatively, when historical events extracted from rainfall data separated by a

27 minimum inter-event time (MIT) criterion are selected based on their total rainstorm depth,

28 the CSO volumes are underestimated significantly; whereas an analysis based on rainstorm

29 maximum intensities over durations similar to the time of concentration provides more

30 conservative volumes. Finally, synthetic storms constructed from multiple points of an IDF

31 curve tend to underestimate slightly the CSO volumes, but provide acceptable results

32 compared to single point derived storms. It was found that the overflow structures local

33 characteristics had a marginal influence on results obtained from continuous simulation

34 compared to event-based simulation. The use of design rainfall events should thus be

35 restricted to preliminary assessment of CSO volume thresholds, and the final volume

36 estimation for solution sizing should be reviewed under continuous simulation. The

37 innovative contribution lies in the improvement of modelling procedures for solutions design

38 to achieve a maximum CSO frequency, such as specified by many regulating agencies.

39 Keywords: Combined sewer overflow; Continuous simulation; Hydraulic modelling; IDF

40 curve; Rainfall data; Retention volume design;

\section{1. Introduction}

42 Sustainable stormwater management in urban areas is essential for water resources quality

43 and viability, municipal infrastructure cost- efficiency and community well-being. Around the

44 world, many urban areas are drained by combined sewer networks that collect and transport

45 both municipal wastewater and stormwater/ snowmelt runoff. During wet weather events or

46 thaw periods, the transport capacity of the system and the treatment capacity of the

47 wastewater facility may be exceeded; resulting in the discharge of untreated wastewater into

48 nearby receiving waters. This phenomenon is commonly described as combined sewer

49 overflows (CSO) and is associated with serious environmental problems and health risks

50 (Gooré Bi et al. 2015b, Madoux-Humery et al. 2015, Passerat et al. 2011). CSO impacts are 
51 expected to worsen in the near future due to projected climate change as well as urban land

52 development (Alves et al. 2016, Semadeni-Davies et al. 2008, Yazdanfar and Sharma 2015).

53 In response to this problem, governments are prescribing regulations to limit the frequency,

54 volume and/or pollutant load of CSOs. For example, since 2014, all sewer extension projects

55 in the Province of Quebec (Canada), such as network densification or the addition of new

56 neighbourhoods in the upstream portions of existing systems, must demonstrate compensatory

57 actions to avoid increasing the annual frequency of sewage overflows (MDDELCC 2014),

58 according to Canada-wide Strategy for the Management of Municipal Wastewater Effluent

59 (CCME 2009). However, only little guidance exists on CSO analysis methods for optimal

60 selection and design of combined sewer solutions. Because CSO frequency, volume and

61 duration are closely linked to rainfall characteristics (Abdellatif et al. 2014, Andrés-

62 Doménech et al. 2010, Mailhot et al. 2015, Montalto et al. 2007, Schroeder et al. 2011,

63 Thorndahl and Willems 2008, Yu et al. 2013), the determination of a robust method for the

64 selection of rainfall information as input data for CSO mitigation analysis is of particular

65 importance.

66 Previous studies analysing the impact of rainfall data on CSO management provide useful

67 information for evaluating possible rainfall input simplifications, estimating flooding risks or

68 comparing scenarios (Calabrò 2004, Fontanazza et al. 2011, Schütze et al. 2002, Thorndahl

69 and Willems 2008, Vaes et al. 2002, Vaes et al. 2001), but not for designing CSO mitigation

70 measures in particular. This work aims to improve modelling procedures for sizing CSO

71 solutions by focussing specifically on the impact of rainfall data on simulated CSO volume

72 thresholds. More specifically, in this paper, the term CSO volume threshold defines the CSO

73 volume that has to be controlled by CSO control solutions designed to achieve a specific

74 maximum annual or seasonal CSO frequency. The objective of this paper is thus twofold:

75 first, to complete an exhaustive review on available types of rainfall input for CSO modelling 
and, second, to evaluate how the application of these different types of rainfall data in a simulation model affects the estimation of CSO volume thresholds for the design of CSO control solutions. To achieve the second objective, the methodology is tested on a real combined sewer network.

\section{Literature review}

In the context of design of CSO control solutions, rainfall data can be divided in two main types: continuous or event-based. Continuous data include chronological wet and dry periods from long-term records whereas event-based data represent individual rainstorm events. Single rainstorm (event-based data) can further be divided into synthetically derived storms or events extracted from historical data. Finally, a fourth type of rainfall data can be derived from a probabilistic modelling approach, in which rainfall data are analysed to identify relationships between a critical rainfall depth threshold and CSO occurrence. The four types of rainfall data, as well as examples of their application for CSO assessment, are subsequently presented.

\subsection{Continuous and quasi-continuous rainfall data}

Continuous simulation of rainfall data consists in using a detailed chronological precipitation record as input to a rainfall-runoff model. A frequency analysis of the resulting runoff output can then be performed to describe the system's response in terms of runoff occurrence and magnitude (Akan and Houghtalen 2003). Considering that the majority of CSO events occur for small, frequently occurring rainfall events and that antecedent conditions such as the soil moisture or the amount of water already in the network can affect the performance of stormwater retention solutions, several authors recommend the use of long-term continuous hydrologic modelling to analyse the system's response for CSO management (Abdellatif et al. 2015, Nilsen et al. 2011, Shoemaker et al. 2011, USEPA 1993, Willems 2011). Quasicontinuous rainfall data described a sequence of seasonal rainfall records when the full annual 
101 time series is either not available or when the seasonality in precipitation characteristics

102 impact CSO processes (for example if there is no rain during winter months).

103 Various modelling studies have applied continuous rainfall data to simulate CSO discharges

104 under baseline and climate change scenarios (Abdellatif et al. 2014, Abdellatif et al. 2015,

105 Dirckx et al. 2017, Nie et al. 2009, Nilsen et al. 2011, Semadeni-Davies et al. 2008); to

106 analyse stormwater control performance for CSO reductions (Dirckx et al. 2011, Lucas and

107 Sample 2015, Montalto et al. 2007, Tavakol-Davani 2016); to validate CSO solution designs

108 (Shoemaker et al. 2011); to address the impact of rainfall spatial variability on CSO volumes

109 (Verwom and Stuecken 2001); to evaluate combined sewer system performance under dry

110 and wet years (Nasrin et al. 2017); or to assess modelling performances for CSO impact

111 estimations (Ruan 1999, Vaes et al. 2001). It could be noted that whereas most studies

112 analysed CSO by comparing resulting volume, duration and/or frequency, the study of Ruan

113 (1999) also assessed water quality impacts of CSOs on receiving waters by evaluating model

114 simulation accuracies for estimating total suspended solids loads and concentrations.

\section{$115 \quad 2.3$ Historical rainfall events}

116 As an alternative to complete continuous simulation, some authors based their research work

117 on event-based simulation of historical rainfall events. Simulating independent rainstorm

118 events reduce the validity of the results if no attention is given to antecedent conditions.

119 Indeed, the cumulative impacts of successive rainfall events in terms of soil moisture,

120 pollutant load, storage levels, remaining capacity of existing stormwater control

121 infrastructures and other variables was found to exacerbate CSO impacts (Hvitved-Jacobsen

122 and Yousef 1988, Mailhot et al. 2015, Vaes et al. 2001).

123 Nevertheless, in terms of both water quantity (CSO peak flow and volume) and quality

124 analysis (CSO pollutant loads and concentrations), observed rainstorm events were previously

125 used as input to simulation models in order to i) assess the effectiveness of best management 
126 practices (BMP) solutions for CSO control (Autixier et al. 2014); ii) assess the impact of

127 climate change by increasing rainfall intensities and comparing the resulting situation with the

128 baseline conditions (Gooré Bi et al. 2015b) also including an analysis of CSO

129 ecotoxicological risks; or iii) investigate relationships between rainfall variables of individual

130 storms and resulting CSOs (Gooré Bi et al. 2015a, Yu et al. 2013).

\section{$131 \quad 2.4$ Synthetic rainfall events}

132 Synthetic rainfall events, or design storms, have been extensively used in the scientific

133 literature as well as in practice for a large spectrum of urban drainage problems. Most

134 commonly used design storms are constructed directly from Intensity-Duration-Frequency

135 (IDF) curves.

136 The total rainfall depth of a synthetic event can be derived from one point of an IDF curve

137 and an arbitrary temporal profile is then applied to distribute the precipitation volume over

138 time. Simpler profiles include rectangular (uniform intensity over the storm duration),

139 triangular(Yen and Chow 1980) and double triangular (DGALN-CEREMA 2014). In the U.S,

140 the Soil Conservation Service distributions (SCS 1968) are four types of 24h-long storms

141 representative of different zones of the country (Types I, IA, II, and III). Other synthetic

142 design storms can also represent all intensity-duration values associated to a specific return

143 period such as the well-known Chicago storm (Keifer and Chu 1957). For most IDF derived

144 storms, the total duration of the storm has to be defined; which is generally greater than the

145 concentration time of the urban catchment or alternatively specified by regulatory agencies

146 (Rivard 1996).

147 Synthetic design storms can be developed by comparing long series of historical storms to

148 define typical temporal distribution of the rainfall. In Canada, common rainstorm profiles are

149 the AES storms of $1 \mathrm{~h}$ (convective storm) and $12 \mathrm{~h}$ (cyclonic storm) developed by the

150 Atmospheric Environment Service (Rousselle 1990) and the HYDROTEK $1 \mathrm{~h}$ 
151 linear/exponential hyetographs of Watt et al. (1986), all derived from the same historical

152 rainfall dataset of Hogg (1980). In the U.S, Huff (1967) developed standardised rainstorms

153 from observed data by defining four types of rainfall distribution according to the timing of

154 the rainstorm peak relatively to the total rainstorm duration and their distribution probability.

155 Yen and Chow (1980) also analysed long series of observed storms and defined

156 dimensionless triangular hyetographs.

157 When the synthetic rainfall is derived from IDF curves, the probability of occurrence of the

158 resulting runoff associated with the synthetic storm is unknown, because IDF relationships are

159 determined from rainfall intensity maxima over a moving time window and does not represent

160 the entire storm event (USEPA 1993; Rivard 1996, Watt and Marsalek 2013). An added

161 uncertainty for the application of synthetic storms is the necessity for the modeller to define

162 some important variables of the rainfall event such as its duration. Finally, the non-linearity of

163 the resulting CSO volumes with rainfall depth could restrict the interpretation of the model

164 response for synthetic storms, because this interpretation implies some sort of linear response

165 between CSO processes and rainfall statistics (Dirckx et al. 2017, Vaes et al. 2001).

166 Previous studies have analysed the performances of BMP as potential solutions for CSO

167 control based on modelling work involving standard design storms of different return periods

168 (Chaosakul et al. 2013, Dong et al. 2017, Fuamba et al. 2010, Mailhot et al. 2014, Sebti et al.

169 2016, Villarreal et al. 2004). Also with the aim of evaluating CSO control measures, other

170 studies developed their own methodology to use available historical rainfall data to construct

171 synthetic rainfall events (Alves et al. 2016, Baek et al. 2015, Shoemaker et al. 2011). Finally,

172 in a more analytical perspective, several authors have simulated various design storms to

173 assess the impact of changing rainfall characteristics on drainage performances in terms of

174 water quantity (Fontanazza et al. 2011, Fu and Butler 2014, Thorndahl and Willems 2008, 
175 Vaes et al. 2002), water quality (Calabrò 2004) or both quantitative and qualitative impacts

176 (Andrés-Doménech et al. 2010).

178 Other research work has analysed long-term sequences of rainfall data to develop statistical

179 relationships between CSOs and rainfall event characteristics without hydrologic and

180 hydraulic modelling tools. Their methodology is based on the hypothesis that there is a

181 critical rainfall depth from which a CSO event has a higher probability of occurring than not

182 occurring (Mailhot et al. 2015). For example, Schroeder et al. (2011) evaluated the

183 effectiveness of certain CSO control measures, whereas Andrés-Doménech et al. (2011) and

184 Fortier and Mailhot (2014) assessed the impact of climate change on combined system

185 performances.

\section{3. Material and methods}

187 This section presents the methodology that was applied to achieve the second objective of this

188 study, namely evaluating how the use of different types of rainfall data impacts CSO volume

189 threshold estimations for CSO frequency reduction.

\section{$190 \quad 3.1$ Study area}

191 The case study is the combined sewer catchment of Thetford Mines, a medium-sized

192 municipality located in the southern part of the Province of Québec, Canada. The drainage

193 network, schematised in Fig. 1, has a catchment area of 401 ha and a concentration time of

194 about $3 \mathrm{~h}$. Almost all the water entering the sewage system is carried by gravity with only one

195 pumping station connecting a small downstream sub-catchment to the rest of the network. The

196 capacity of the main interceptor is highly restricted by its small diameter and the maximum

197 capacity of the wastewater treatment plant (WWTP). There are a total of 30 overflow

198 structures discharging wastewater to either one of the two receiving rivers of the area. For this

199 municipality, the provincial legislation recommends a maximum of seven CSO spills per year 
under wet weather conditions between May to November, considering that overflows are

201 recorded on a daily basis. The analysis was carried out for 10 of these 30 overflow structures

202 (identified in Fig. 1), because they often exceed the permitted occurrence and runoff control

203 solutions have not yet been implemented at these structures, as is the case for the remaining

204 structures.

205 [Fig. 1. Combined sewer network and selected CSO structures]

$206 \quad 3.2$ Historical CSO data

207 In the Province of Québec, CSO frequency and sometimes duration data are reported annually

208 to the Ministry of Municipal Affairs and Occupation of the Territory (MAMOT) for each

209 CSO overflow structures and WWTP stations. High uncertainty is attached to observed CSO

210 data. For the majority of the overflow structures monitored from 2006 to 2015, the occurrence

211 of CSOs is determined approximately on a weekly basis. A municipal employee visits the

212 overflows structures and indicates that at least one overflow as occurred since the last visit if a

213 visual floating device has been moved by the water from the manhole to the overflow pipe.

214 Among all the CSO structures in the study catchment, only the one at the WWTP has been

215 historically recorded on a daily basis by automated devices. All the others have been recorded

216 by intermittent weekly visits. The total volume of CSOs is not monitored on this network.

\section{$217 \quad 3.3$ Hydrologic/hydraulic model}

218 The research methodology is based on the modelling of hydrologic and hydraulic processes

219 using PCSWMM software (CHI 2016) derived from EPASWMM (Rossman and Huber

220 2016). The case-study network has about 1360 links and 1310 nodes, totalizing $78000 \mathrm{~m}$ of

221 conduits length. The sub-catchments average slope is $2.8 \%$ and total impervious area is about

$22232 \%$. The low imperviousness is due to the success of a municipality wide gutter

223 disconnection campaign and the number of pseudo and separated sub-catchment areas. The

224 model was developed and calibrated for wet weather and dry weather events measured in 
2006 and 2009 by the consulting engineering firm Tetra Tech CSO (formally BPR CSO)

226 based in Québec City, Canada (Marcoux et al. 2011 ). For wet weather flows calibration, the

227 directly connected impervious areas of the combined sewer sub-catchments, as well as the

228 characteristic width of overland flow, the sub-catchment superficies and initial rainfall

229 abstraction depths for both combined and separate sewer sub-catchments were adjusted using

230 three to four distinct rainfall events. Calibration criteria were based on James (2003): 1) \pm 20

$231 \%$ for runoff volumes, 2) $\pm 15 \%$ for peak flows, 3$) \pm 10$ min for peak flow synchronism, and

232 4) $\pm 0.10 \mathrm{~m}$ for measured water levels. The RDII unit hydrograph method (Rossman and

233 Huber 2016) was utilized to account for rainfall dependent inflow and infiltration into the

234 combined sewers. In the case of dry weather inflows, a constant infiltration flow was added

235 upstream of each overflow structure (Marcoux et al. 2011). Similarly, domestic wastewater

236 flows were simulated based on hourly fluctuation patterns determined at each measurement

237 point during the calibration campaigns.

238 To estimate the volume of CSO per event, the simulated overflow volume time series for each

239 structure was extracted from the modelling outputs. If an event started earlier than midnight

240 and extended over the following day, it was compiled as two CSO events to mimic historical

241 CSO recording procedure.

$242 \quad 3.4$ Rainfall data

243 Three rain gauge stations have been operated by the municipality since 2004 . At these

244 stations, the rainfall data measured by a tipping bucket are recorded every 5 min and were

245 validated by comparing the records with those of a station operated by Environment Canada

246 and located about $4 \mathrm{~km}$ from the studied catchment. Years 2004, 2005 and 2010 were rejected

247 from the analysis due to missing data or invalidated total seasonal rainfall depth, which leads

248 to a total of nine years of rainfall data (2006-2009 and 2011-2015). For each of these years,

249 the analyses were performed from May to November, since winter months are excluded from 
250 Quebec legislation limiting CSO occurrence. Therefore, the available precipitation data are

251 considered as a quasi-continuous rainfall record, which should permit to represent with

252 enough accuracy historical conditions leading to CSOs in the study catchment.

253 The model validation for CSO frequency estimations was done using the quasi-continuously

254 recorded data from the three rain gauges for more accurate spatial representation of historical

255 rainfall conditions. However, the following study results are based on only one rain gauge

256 (see Fig. 1 for location), because the impact of changing the rainfall data input on CSO

257 volume estimations for CSO control is better isolated by assuming that the rain is uniformly

258 distributed over the whole study area. Over the study period, seasonal (May to November)

259 rainfall depths at this location ranged from 730 to $960 \mathrm{~mm}$.

\subsection{Rainfall data selection methods compared for retention volume design}

261 The impact of applying different rainfall inputs on CSO volume thresholds determination for

262 CSO control was evaluated to achieve a specific maximum number of CSOs per year. This

263 frequency performance goal is selected rather than water quality objectives or percentage of

264 capture in order to be consistent with the current legislation applicable in the Province of

265 Québec. The following paragraphs describe three rainfall data selection methods, one of

266 which has two variants.

$267 \quad 3.5 .1 \quad 1^{\text {st }}$ method: Quasi-continuous simulation

268 The first method analysed consisted of applying quasi-continuous simulation of available

269 sequence of seasonal rainfall data. A frequency analysis of simulated CSO time series

270 permitted to determine the seventh maximum CSO volume from each simulated year

271 separately. Subsequently, the maximum value among all years was selected in order to obtain

272 the CSO volume threshold for the design of retention solutions to ensure a maximum of seven

273 spills per year.

274 An assessment of the sensitivity of the results to the number of years taken into account in the 
analysis was also realized. The aim was to evaluate how the inter-annual variability of rainfall conditions could influence CSO volume thresholds for CSO management, when only a few years of data are available for the analysis. All combinations of years were tested for all the possible simulation lengths ranging from one to nine years (corresponding to the whole available data for this case study).

\subsection{2 $2^{\text {nd }}$ method: Historical rainstorm events based on a) total depth and b) maximum} intensity

The second method assessed the impact of applying event-based simulation by extracting particular rainstorms from the historical rainfall records. This type of rainfall data analysis was performed, because some engineers use this method or an equivalent as it requires less computational effort than complete continuous simulation.

The method consists in separating the available rainfall record into distinct events. Several event separation methods exist based on rainfall intensity, statistical properties, duration percentage or set dry period criteria in order to extract from the continuous rainfall data individual rainstorm events (Powell et al. 2007). The most common and simple one consists in determining each event bounded by fixed rain-free intervals of minimal duration, usually referred to as the minimum inter-event time (MIT). The selected MIT criterion requires to be identified according to the simulation objective as it has been proved to have a large impact on the resulting rainstorm event characteristics (Dunkerley 2008). The Quebec government suggests a MIT of $6 \mathrm{~h}$ to separate meteorological events from one another (MDDEP 2010) but recommend an emptying time for retention structures of $24 \mathrm{~h}$. Therefore, to cover a broad range of design criteria, the impact of selecting 3, 6, 12 and $24 \mathrm{~h}$ MIT values on rainstorm event separation and CSO volume assessment was analysed. Table 1 presents the main characteristics of the rainfall events for each MIT criterion.

Table 1. Mean rainfall event characteristics for MIT=3, 6, 12 and $24 \mathrm{~h}$ 


\begin{tabular}{rrrrrrr}
$\begin{array}{r}\text { Minimum } \\
\text { inter-event } \\
\text { time (MIT) } \\
(\mathrm{h})\end{array}$ & $\begin{array}{r}\text { Mean } \\
\text { number of } \\
\text { rainfall } \\
\text { events per } \\
\text { year } \\
{[\text { May- }}\end{array}$ & $\begin{array}{r}\text { Mean rainfall } \\
\text { event depth } \\
(\mathrm{mm})\end{array}$ & $\begin{array}{r}\text { Mean rainfall } \\
\text { event intensity } \\
(\mathrm{mm} / \mathrm{h})\end{array}$ & $\begin{array}{r}\text { Mean maximum } \\
\text { rainfall intensity } \\
\text { during 5 min } \\
(\mathrm{mm} / \mathrm{h})\end{array}$ & $\begin{array}{r}\text { Mean } \\
\text { rainfall } \\
\text { duration } \\
(\mathrm{h})\end{array}$ & $\begin{array}{r}\text { Mean dry } \\
\text { inter-event } \\
\text { duration } \\
(\mathrm{h})\end{array}$ \\
\hline 3 & 142 & 6 & 2.5 & 9.9 & 3.9 & 32.1 \\
\hline 6 & 105 & 8 & 2.2 & 11.8 & 6.8 & 41.5 \\
12 & 75 & 11 & 1.7 & 14.0 & 13.0 & 54.8 \\
24 & 53 & 16 & 1.3 & 16.9 & 25.4 & 70.5 \\
\hline
\end{tabular}

300

301 The design rainstorms were then selected among the MIT-separated series by frequency

302 analysis based on two event selection criteria: a) the total rainstorm depth; and b) rainfall

303 maximum intensities over various durations as described below.

304 For historical rainstorms selected based on total rainfall depth, a frequency analysis was

305 conducted on the four MIT-separated rainfall time series to determine the seventh largest

306 rainstorms, in terms of total precipitation depth, for every year. Among the selected events,

307 the rainstorm having the maximum total depth was considered as the design rainfall event to

308 achieve the CSO frequency target. The hypothesis was that CSO events behave linearly with

309 rainfall depth. Other authors also linked rainfall depth with CSO volume based on linear

310 regression analysis of simulated CSO and rainfall data (Alves et al. 2016, Baek et al. 2015).

311 Moreover, similarly to this assessed rainfall selection method, Shoemaker et al. (2011)

312 identified a design storm for CSO solutions sizing by determining from a one-year rainfall

313 record the two-month return period historical storm based on total rainfall depth separated by

314 a $12 \mathrm{~h}$ inter-event spacing. Their study was applied to quantify the storage capacity required

315 to achieve a maximum number of six CSO events per year in a combined sewer network of

316 Kansas City (USA).

317 For historical rainstorms selected on maximum intensity, a frequency analysis was done on

318 the same four MIT-separated rainfall series to identify the rainstorms having the maximum 
rainfall intensity (Imax) over durations of 30, 60, 120 and $180 \mathrm{~min}$. Several duration values

320 were analysed to evaluate how the $\mathrm{CSO}$ volumes varied according to a range of rainfall

321 intensities. The aim is to compare historical rainstorms not only in terms of rainfall depth (as

322 it was done previously) but in terms of sustained intensities. The added value of this method

323 is to avoid selecting a rainfall event having a large total rainfall depth over a long duration,

324 which would result in low average rainfall intensity and might not have the same impact on

$325 \mathrm{CSO}$ as a more compact rainfall event. The rainfall event series was ordered to determine the

326 maximum annual seventh rainstorms in terms of Imax for each duration. Among those

327 seventh rainstorms for all years in the analysis, the one having the maximum Imax was

328 selected as the design rainstorm, for each duration. As a comparison, Mailhot et al. (2015)

329 used daily maximum rainfall values of $5 \mathrm{~min}$ to $12 \mathrm{~h}$ durations to establish a predictive

330 threshold model associating observed rainfall depth over these durations and CSO occurrence

331 probability. However, because their model describes the CSO probability for the actual

332 conditions of the system, it does not permit to further determine CSO volume thresholds for

333 reducing CSO frequency to specified targets. Sandoval et al. (2013)'s empirical study also

334 analysed the link between CSO and rainfall maximum intensities and found that it was the

335 most influent driver of CSO quantity at the main CSO outlet of the city of Berlin (Germany).

$336 \quad 3.5 .3 \quad 3^{\text {rd }}$ method: IDF derived storms

337 Finally, the third method is based on IDF relationships, which is representative of current

338 practice in the industry. The method consists in determining rainfall intensity values for

339 frequent events over various durations, as opposed to mostly available IDF curves developed

340 for long return periods (2-100 years). The intensity values are identified by selecting the

341 maximum rainfall intensity that has occurred for various windows of time $(5,10,15,30,60$,

$342120,360,720$ and $1440 \mathrm{~min}$ ) for each day of the rainfall record such as suggested by

343 (MDDELCC 2017). A frequency analysis is then performed for each duration to determine 
344 the rainfall intensities having a return period of seven times per season from May to

345 November (or once a month) by selecting the 63 th value of the ordered series ( 7 times/season

$346 \times 9$ seasons).

347 The identified rainfall intensities for the nine assessed durations (5 to $1440 \mathrm{~min}$ ) are used to

348 derive an IDF regression curve of a return period of seven times per season. Based on the

349 fitted IDF parameters, Chicago hyetographs are developed with a symmetrical centred peak

350 and for three storm durations: $1 \mathrm{~h}, 3 \mathrm{~h}$ and $6 \mathrm{~h}$. Symmetrical Chicago storms were applied

351 rather than unsymmetrical storms as the goal of this study is to assess conceptually how

352 various types of widely applied design storms impact the simulated results in a solution

353 design perspective. A time step of $10 \mathrm{~min}$ is considered as suggested by the literature to avoid

354 excessive rainfall intensity (Rivard 2005).

355 In addition to the Chicago storms, other $1 \mathrm{~h}$ and $3 \mathrm{~h}$-synthetic hyetographs were further

356 applied to a single IDF value as currently done in urban infrastructure design. For these

357 synthetic hyetographs, the total rainfall depth was determined by using the rainfall intensity

358 associated with a duration of one hour and a return period of seven times per season. The total

359 rainfall depth is then distributed according to standard hyetograph shapes available in the

360 literature for the case study location: 1) Hydrotek (Rousselle et al. 1990), 2) AES type 2

361 (Rousselle et al. 1990), and 3) uniform distribution (rectangular). It could be noted that the

362 Hydrotek and AES storms are unsymmetrical. The aim was to assess the impact on retention

363 volumes of using synthetic storms constructed from multiple IDF points (Chicago storms) and

364 single IDF point (synthetic hyetographs).

365 4. Results and discussion

$366 \quad$ 4.1 Simulated versus observed data

367 Simulated CSO events were compared to observed data in order to assess the model accuracy.

368 As proposed by Jolliffe and Stephenson (2012), the proportion of correct estimation of a 
binary event is evaluated (occurrence or non-occurrence of a CSO). This type of analysis

370 permits to highlight false positives (number of weeks/days for which a CSO event is

371 simulated when no CSO was recorded) and false negatives (number of weeks/days for which

372 no CSO is simulated when a CSO event has been observed) from true estimations (number of

373 weeks/days for which simulated results correspond to observed ones). Fig. 2 presents the

374 results, where true overflow estimations are summed up for each structure and each year to

375 compare the proportion of correct values. Lower proportion of correct estimation values are

376 usually associated with observed data having a high standard deviation, which means that the

377 inter-annual variability might be a result of other causes than rainfall variation such as CSO

378 monitoring deficiencies. For example, the years 2007 and 2011 present similar rainfall

379 characteristics in terms of rainfall events frequency and magnitude, but historical recorded

380 CSO events per overflow structure reach 25 on average for the year 2007 and only 11 for the

381 year 2011. As a consequence, the proportion of correct estimations for the years 2011 is much

382 lower, but should probably be associated to data recording deficiencies rather than modelling

383 inaccuracy. The best correlation between observed and simulated values were obtained for the

384 overflow structure associated with the WWTP which is the structure having the best historical

385 data available for comparison. It is believed that with more accurate observed data for the

386 other overflow structures (CSO event monitored at a daily basis rather than every week), a

387 better estimation of CSO frequency might also be obtained. The recent report of (Cliche and

388 Saladzius 2018) denoted a drastic increase in CSO frequencies in 2016 compared to the years

3892014 and 2015 for the same municipality as our case study. The installation of daily

390 monitoring equipment in 2015 (Personal communication with municipal engineer, 2016)

391 probably explains the increase in overflow events reported by Cliche and Saladzius (2018)

392 and could lead to a better comparison of historical and simulated CSO in the future.

393 Therefore, considering the high uncertainty attached to observed data and the hydrological 
394 and hydraulic calibration performed for wet and dry periods (see section 3.3), the model is

395 considered adequate to simulate CSO events.

396 [Fig. 2. Mean of correctly simulated CSO events for selected overflow structures and the

397 WWTP. Note: The error bars show the annual maximum and minimum percentage of correct

398 estimations. The dashed line shows the average annual proportion of correct estimations for

399 the 10 selected overflow structures.]

$400 \quad 4.2$ Quasi-continuous simulation

401 Time series of CSO events based on simulation of a sequence of continuous seasonal rainfall

402 data capture the spatial heterogeneity of the system under various rainfall conditions. Table 2

403 presents the average number of CSO spills per year and their associated maximum CSO

404 volumes and average seasonal percentage of rainfall overflowing, which vary considerably

405 from one structure to another. As shown, there is a high gap between simulated numbers of

406 CSOs and the target value of seven CSOs per year as prescribed by the regulations applicable

407 for the case study. Indeed, this network is highly restricted in the volume of wet weather flow

408 that could be effectively transported in the main interceptor. Applying quasi-continuous

409 simulation allows determining a specific CSO volume threshold for each sub-section of the

410 catchment, because the CSO frequency analysis is conducted separately for each structure.

411 Indeed, most of the time the causing rainfall event of the determined CSO volume threshold

412 for each overflow structure is not the same rainfall event. The calculated CSO volume

413 thresholds determined for a maximum number of seven CSO spills per year per overflow

414 structure are presented in Table 2 and are considered as reference values for comparison with

415 the following rainfall selection methods.

416 The application of a longer dataset would better account for extreme values. However,

417 considering that continuous simulation of seasonal rainfall records includes a broad variety of

418 antecedent conditions and rainstorm characteristics, it is believed that this method provides 
419 adequate CSO volume estimations for the design of solutions achieving specific CSO control

420 targets. Similarly, Vaes et al. (2001) found that most adequate results for CSO assessment

421 were obtained from simplified conceptual models in combination with continuous long term

422 simulations.

423 Table 2. CSO modelling results under quasi-continuous simulation

\begin{tabular}{|c|c|c|c|c|}
\hline $\begin{array}{c}\text { Overflow } \\
\text { structure }\end{array}$ & $\begin{array}{r}\text { Average } \\
\text { number of } \\
\text { CSO spills per } \\
\text { year }\end{array}$ & $\begin{array}{r}\text { Maximum CSO } \\
\text { volume per event } \\
\text { from } \\
\text { all years } \\
\left(\mathrm{m}^{3}\right)\end{array}$ & $\begin{array}{r}\text { CSO volume threshold } \\
\text { for } 7 \text { spills/year } \\
\text { maximum } \\
\left(\mathrm{m}^{3}\right)\end{array}$ & $\begin{array}{r}\text { Average percentage of } \\
\text { seasonal rainfall } \\
\text { overflowing under } \\
\text { quasi-continuous } \\
\text { simulation } \\
(\%) \\
\end{array}$ \\
\hline A & 25 & 518 & 102 & 1.8 \\
\hline B & 62 & 1,758 & 505 & 13.2 \\
\hline $\mathrm{C}$ & 35 & 542 & 125 & 6.1 \\
\hline $\mathrm{D}$ & 65 & 8,535 & 2,574 & 19.6 \\
\hline E & 54 & 4,671 & 1,297 & 10.0 \\
\hline $\mathrm{F}$ & 13 & 190 & 38 & 11.5 \\
\hline $\mathrm{G}$ & 58 & 1,079 & 336 & 2.3 \\
\hline $\mathrm{H}$ & 63 & 3,336 & 1,064 & 23.6 \\
\hline I & 60 & 2,413 & 650 & 18.8 \\
\hline $\mathrm{J}$ & 57 & 2,786 & 807 & 2.4 \\
\hline Total & 494 & 25,827 & 7,498 & \\
\hline
\end{tabular}

425 The impact of using a few years for the analysis of CSO under quasi-continuous simulation

426 was assessed by simulating all possible combination of years among the available nine years

427 of seasonal data for one to nine years-long simulation length. Fig. 3 shows the median values

428 of the total CSO volume thresholds estimated for the ten structures to achieve the CSO

429 control objective (i.e. maximum of 7 spills per season). Logically, with a larger sample of

430 years used as input data, the rainfall inter-seasonal variability is greater. As a consequence,

431 the determined volume should be greater by accounting for more extreme CSO events.

432 Median values can vary from about 6,500 to $7,500 \mathrm{~m}^{3}$. Data dispersion is illustrated through

433 error bars which decrease according to the number of years simulated. More specifically, if

434 only one year is simulated among the nine years available, the volume design could be

435 considerably underestimated as the smallest CSO volume threshold could equal $4,900 \mathrm{~m}^{3}$; a 
difference of $35 \%$ with the largest value obtained from the simulation of all the available

437 years.

438 Another important point raised by this sensitivity analysis, is the difficulty to determine which 439 year(s) should be simulated among the available data. For example, two selection criteria 440 were applied to the available series to determine which year would most likely produce the 441 greatest CSO volumes. Fig. 4 presents CSO volume thresholds for each structure based on the 442 simulation of the wettest year (2011), as well as the year having the most frequent large ( $\geq 30$ $443 \mathrm{~mm}$ ) rainfall events (2015). In Fig. 4, the CSO volumes obtained are also compared with the 444 results from continuous simulation of seasonal rainfall records and other rainfall selection 445 methods. As shown, the selection of the year having the most frequent large rainfall events 446 provide a more conservative estimation of CSO volume threshold for solution design, because 447 those events are more likely to produce important overflow volumes. Nevertheless, the added 448 value of continuous simulation can only be fully considered when all available data are taken 449 into account rather than reducing the analysis to a single year, because it guaranties obtaining 450 the critical CSO volume for each overflow structure individually among the simulated years.

451 [Fig. 3. Sensitivity to the number of years simulated of the total CSO volume thresholds estimated for the ten overflow structures]

453 [Fig. 4. Comparison of rainfall data selection methods for determining CSO volume 454 thresholds from simulation]

\subsection{Historical rainstorm events}

456 Simulation of specific historical rainfall events was performed using the total rainfall depth 457 per event, and then the Imax over 30, 60, 120 and 180 min from the MIT-separated rainfall 458 series. 


\subsubsection{Historical rainstorms selected based on total rainfall depth}

460 Since four MIT criteria were applied (3, 6, 12 and $24 \mathrm{~h})$ to the rainfall record in order to

461 extract individual rainstorm events, four rainfalls were identified as design storms. Fig. 4

462 presents the simulated CSO volumes for each structure under the four rainfall events, along

463 with a comparison with quasi-continuous simulation results and other rainfall selection

464 methods. Except for the value of $24 \mathrm{~h}$, simulation of the maximum annual seventh greatest

465 rainstorm in terms of total rainfall depth underestimated the CSO volumes as compared to

466 quasi-continuous simulation. Even if the simulated rainstorms are characterized by a high

467 total rainfall depth, their extended duration resulted in much lower average rainfall intensities

468 and CSO spilled volumes. For a better assessment of resulting CSO volumes, Fig. 5 presents

469 the rainfall depth and total CSO volumes for the seventh greatest events determined for each

470 year separately. All these rainstorms are characterized by a large total rainfall depth but have

471 varying durations and average rainfall intensities. As illustrated, similar rainstorms in terms of

472 total rainfall depth led to highly variable CSO volumes. Results showed no linear relationship

473 between total rainfall depths and CSO volumes, explaining partly why results presented in

474 Fig. 4 are considerably below the ones estimated from quasi-continuous simulation.

475 Yu et al. (2013) also found that moderate rainstorms, in terms of rainfall total depth, have

476 poor correlation with CSO occurrence. According to these authors, rainstorms of high and

477 low depths better correlate with CSO occurrence or non-occurrence, respectively, based on

478 the analysis of 117 rainfall events extracted from a one year long record in Tokyo (Japan).

479 Similarly, Gooré Bi et al. (2015a) observed high correlations between rainstorm total depth

480 and CSO event pollutant load by analysing the correlation between rainfall variables and

481 water quality indicators monitored during CSO events. 
483 The four MIT-separated rainstorms series were then used for design rainfall event selection 484 based on Imax over 30, 60, 120 and 180 min. Fig. 4 presents the simulated CSO volumes for 485 all the seventh greatest rainstorms for various Imax durations and MIT values. However, 486 because the same critical events were identified for both MIT $=3 \mathrm{~h}$ and $6 \mathrm{~h}$, only the results 487 obtained from the MIT=3h series are presented in order to avoid redundancy. As shown, 488 estimated CSO threshold volumes are either higher or lower than the volumes determined by 489 continuous simulation of seasonal rainfall records. Schütze et al. (2002) indicated that 490 information on CSO frequency from event-based simulation may be highly inaccurate for 491 non-linear systems, which seems the case here.

492 As a consequence of the disputable linearity between CSO volume and rainstorm total depth 493 or intensity, CSO volume threshold calculations based solely on the total depth or intensity of 494 rainfall events would not guarantee adequate volume estimations for design.

495 [Fig. 5.Total CSO volume thresholds for the ten overflow structures based on the annual $4967^{\text {th }}$ greatest rainstorms in terms of total rainfall depth and MIT=3, 6, 12, and 24h]

\subsection{IDF derived storms}

498 The last assessed method focussed on event-based simulation of synthetic design storms. The 499 analysis of daily maximum rainfall intensities record permitted to characterise IDF

500 relationships having an estimated recurrence of seven times per year. Cumulative rainfall

501 depths for the three Chicago storms are respectively 25.2, 30.1 and 33.6 mm. For the other

502 tested standardised hyetographs, a cumulative rainfall depth of $10.5 \mathrm{~mm}$ was applied for the 1

503 h-duration and $19.0 \mathrm{~mm}$ for the 3 h-duration, both determined by frequency analysis for a 504 return period of $1 /$ month.

505 Fig. 4 presents the resulting CSO volumes, compared to those obtained from other rainfall 506 selection methods. The event-based results were slightly lower than the CSO volumes 
507 determined by quasi-continuous simulation in the case of Chicago storms of 3 or 6 hours-

508 duration; whereas single IDF value derived storms noticeably underestimated CSO volume

509 thresholds. Single 1h-IDF value derived storms all had a different time distribution of the rain,

510 but led to similar simulated CSO volumes, even in the case of a uniform rainstorm. Even if

511 the uniform 3h-storm has the same duration as the time of concentration of the catchment, it

512 still underestimated the total CSO volume compared to quasi-continuous simulation. When

513 simulating single events, the results show that the total volume of the design storm has an

514 impact on the resulting CSO volumes whereas the hyetograph shape has almost none.

515 Differences in volume obtained from synthetic events compared with quasi-continuous

516 simulation can be explained partly by the uncertainty associated with the application of IDF

517 derived design storms. Drawbacks of applying design storms for CSO control design include

518 the necessity to decide on the duration of the simulated event and its return period (Watt and

519 Marsalek 2013).

520 For comparison, Calabrò (2004) denoted that applying Chicago and triangular shape storms

521 having durations similar to the time of concentration of the catchments, resulted in higher

522 overflow discharges to receiving water bodies compared to rectangular storms and longer

523 storms. On the other hand, Vaes et al. (2001) specifically indicated that the non-linearity of

524 the system response (when the outflows are not directly linked to the storage capacity of the

525 catchment) increased for design storms having a high recurrence compared to lower

526 recurrence ones, thus limiting application of design storms for CSO control. Guo (2001)

527 concluded that design storms provided simulation results generally close to continuous

528 simulation when sizing flood control detention ponds for the city of Chicago, Illinois. The

529 design criteria of his study was however based on large return periods (100 years), which is

530 quite different from our small return period criterion. Müller et al. (2017) found that rainfall

531 events' asymmetry has an impact on CSO statistics such as discharged volume, concluding on 
532 the importance that synthetic time series should represent observed rainfall asymmetry.

533

534 The CSO volumes threshold simulated under the different rainfall data selection methods

\subsection{Comparison of simulated results per overflow structures} compared previously were lastly analysed more thoroughly per overflow structure. The aim

was to evaluate if the local characteristics associated to each structure could have an influence on the relative performance of one method compare to another. Table 3 provides local characteristics of the ten assessed overflow structures as well as the minimum and maximum simulated CSO volume threshold. As shown, larger tributary area or higher impervious area coverage does not necessary lead to higher overflows in terms of maximum simulated volumes by the assessed rainfall selection methods. The number of overflows structures located upstream and the regulated maximum flowrate capacities seem to help in reducing overflow volume. For example, structure $\mathrm{J}$ has the highest tributary area and a relatively high imperviousness, but its maximum simulated overflow volume threshold is almost the same as for overflow structure B, which is located at the outlet of a much lower area but has limited regulation capacity.

Fig 6 shows for all overflows structures the percentage difference in simulated CSO volume thresholds of each method with the results from quasi-continuous simulation. It could be seen that the overflow structures B, D, E, G, H, I and J follow generally the same tendency, i.e. have similar increasing or decreasing CSO volume trends for the same assessed method whereas the overflow structures A, C and F are generally outliers. These three structures are associated to the smallest overflow frequencies and volumes (see Table 2). Interestingly, the remaining structures have local characteristics varying greatly but that did not seem to impact much the general trends of the results.

Fig. 6 also permits to highlight that simulating a continuous record of just one season (the wettest year or the year having the most frequent large rainfall events) provide an estimation 
557 of critical CSO volume closer to those obtained under quasi-continuous simulation of the full

558 record of years available (\% difference in volumes closer to zero) compared to event-based

559 simulation results and with and with almost no influence from the structures local

560 characteristics. All the remaining methods consisting of simulating one single historical or

561 synthetic rainfall event do perform not as well and the individual results for each overflow

562 structure are generally more widely distributed. Finally, by looking at the methods falling

563 between the $\pm 25 \%$ marks indicated by dashed lines in Figure 6 , it could be noticed that the

564 Chicago storms of 3 or $6 \mathrm{~h}$ as well as the historical rainstorms selected based on rainfall

565 maximum intensity over longer durations (180 minutes and sometimes 120 minutes) provide

566 more acceptable results than the remaining methods for a majority of the overflow structures.

567 Table 3. Local characteristics of overflow structures

\begin{tabular}{|c|c|c|c|c|c|c|c|}
\hline $\begin{array}{l}\text { Overflow } \\
\text { structure }\end{array}$ & $\begin{array}{r}\text { Maximum } \\
\text { capacity } \\
\text { of } \\
\text { regulator } \\
\text { upstream } \\
\left(10^{-3} \mathrm{~m}^{3} / \mathrm{s}\right)\end{array}$ & $\begin{array}{l}\text { Tributary } \\
\text { area (ha) }\end{array}$ & $\begin{array}{r}\text { Impervious } \\
\text { area }(\%)\end{array}$ & $\begin{array}{r}\text { Number } \\
\text { of } \\
\text { overflow } \\
\text { structure } \\
\text { upstream }\end{array}$ & $\begin{array}{r}\text { Concentration } \\
\text { time } \\
(\mathrm{HH}: \mathrm{MM})\end{array}$ & $\begin{array}{r}\text { Minimum } \\
\text { simulated } \\
\text { CSO } \\
\text { volume } \\
\text { from all } \\
\text { assed } \\
\text { methods } \\
\left(\mathrm{m}^{3}\right) \\
\end{array}$ & $\begin{array}{r}\text { Maximum } \\
\text { simulated } \\
\mathrm{CSO} \\
\text { volume } \\
\text { from all } \\
\text { assed } \\
\text { methods } \\
\left(\mathrm{m}^{3}\right) \\
\end{array}$ \\
\hline A & 3.4 & 9.99 & 25.5 & 1 & 01:40 & 0 & 119 \\
\hline B & 4.3 & 10.68 & 25.4 & 1 & $00: 30$ & 167 & 814 \\
\hline $\mathrm{C}$ & 3.6 & 3.80 & 19.4 & 0 & $00: 30$ & 0 & 147 \\
\hline $\mathrm{D}$ & 25.1 & 37.49 & 32.6 & 0 & 01:00 & 963 & 4110 \\
\hline $\mathrm{E}$ & 23.5 & 32.86 & 20.8 & 1 & $00: 45$ & 293 & 1929 \\
\hline $\mathrm{F}$ & 5.5 & 0.47 & 100 & 0 & 01:00 & 0 & 49 \\
\hline $\mathrm{G}$ & 30.8 & 40.26 & 33.3 & 1 & 01:00 & 96 & 497 \\
\hline $\mathrm{H}$ & 10.1 & 12.68 & 37.3 & 0 & 01:00 & 374 & 1684 \\
\hline I & 11.4 & 9.77 & 31.2 & 0 & $00: 45$ & 143 & 1005 \\
\hline $\mathrm{J}$ & 77.0 & 93.36 & 27.8 & 3 & $02: 15$ & 242 & 1167 \\
\hline
\end{tabular}

568

569 [Fig. 6. CSO volume thresholds difference of all rainfall selection methods with quasi-

570 continuous simulation per overflow structures. Note: The dashed lines show the limits for a

$571 \quad$ volume difference of $\pm 25 \%$.] 
573 This study addressed the knowledge gaps on the proper use of available rainfall data for

574 sizing CSO reduction solutions. Actual rainfall data selection methods for CSO analysis and

575 management were described and include continuous simulation, synthetic design storms,

576 historical rainfall events, and rainfall depth threshold. Thereafter, three rainfall data selection

577 methods for volume design of stormwater control solutions to comply with a specific

578 maximum annual CSO frequency were compared.

579 The first method was quasi-continuous simulation of the nine years of available seasonal

580 precipitation record, which permitted to obtain CSO volume threshold values for each

581 overflow structures separately. However, reducing the number of years in the analysis rapidly

582 impacted the estimated volumes due to the loss of inter-annual variability of rainfall data.

583 Alternatively, continuous simulation of the seasonal record of a single year having the most

584 frequent rainstorms exceeding a specific total rainfall depth can give a good approximation of

585 CSO volumes for solution design and without distinction of overflow structures local

586 characteristics.

587 For the second rainfall selection method, the design rainstorms were identified based on either

588 their total rainfall depth or their maximal rainfall intensity for durations of $30,60,120$ or 180

589 min. CSO volume thresholds were obtained under event-based simulation of the selected

590 critical events. The high inter-events variability of the simulation results demonstrated the

591 non-linearity of CSO volumes with the rainfall event characteristics (total depth or maximum

592 intensities) and its disputable applicability as design criteria for CSO control.

593 Finally, simulated CSOs under Chicago storms derived from rainfall daily maxima resulted in 594 an underestimation of CSO volume thresholds. On the other hand, the simulation of other

595 standard synthetic storms (Hydrotek, AES type 2, and uniform $1 \mathrm{~h}$ storms) having a total

596 rainfall volume equivalent to a single IDF value underestimated more drastically the CSO 
597 volumes. Under single event simulation for CSO control purpose, design storms involving

598 multiple IDF values such as Chicago storms should be prioritized. However, it is still difficult

599 to determine the best design storm duration as this factor could considerably affect the results.

600 Because CSO processes are site specific and sensitive to a variety of rainfall characteristics, it

601 is difficult to identify one design event that will ensure compliance with specific annual CSO

602 frequency for design guidelines. Therefore, it is recommended that the use of design rainfall

603 events should be restricted to preliminary assessment of CSO control measures, whereas the

604 final solution sizing should be reviewed under continuous simulation or quasi-continuous

605 simulation to ensure appropriate volume estimations. CSO analysis would definitely benefit

606 from larger rainfall datasets. Further work could focus on integrating CSO volume

607 calculations with solution type, location and operation on a river basin scale for refining CSO

608 control design.

609 Acknowledgments: The authors gratefully acknowledge the technical support of Christiane

610 Marcoux and Leni Trudel at Tetra Tech CSO as well as Daniel Cyr, chief of Engineering and

611 Environment in the municipality of Thetford Mines. This study was funded by research grants

612 from the Eau Terre Environnement Research Centre (Institut National de la recherche

613 scientifique) and from the Natural Sciences and Engineering Research Council of Canada.

614 The authors are grateful to Computational Hydraulics Int. for PCSWMM software license.

615 Figure captions:

616 Fig. 1. Combined sewer network and selected CSO structures

617 Fig. 2. Mean of correctly simulated CSO events for selected overflow structures and the

618 WWTP. Note: The error bars show the annual maximum and minimum percentage of correct

619 estimations. The dashed line shows the average annual proportion of correct estimations for

620 the 10 selected overflow structures. 
621 Fig. 3. Sensitivity to the number of years simulated of the total CSO volume thresholds

622 estimated for the ten overflow structures

623 Fig. 4. Comparison of rainfall data selection methods for determining CSO volume thresholds 624 from simulation

625 Fig. 5. Total CSO volume thresholds for the ten overflow structures based on the annual $7^{\text {th }}$ 626 greatest rainstorms in terms of total rainfall depth and MIT=3, 6, 12, and $24 \mathrm{~h}$

627 Fig. 6. CSO volume thresholds difference of all rainfall selection methods with quasi628 continuous simulation per overflow structures. Note: The dashed lines show the limits for a 629 volume difference of $\pm 25 \%$.

630 References

631 Abdellatif, M., Atherton, W. and Alkhaddar, R. (2014) Assessing combined sewer overflows 632 with long lead time for better surface water management. Environ Technol 35(5-8), 568-580. 633 Abdellatif, M., Atherton, W., Alkhaddar, R. and Osman, Y. (2015) Quantitative assessment of 634 sewer overflow performance with climate change in northwest England. Hydrological 635 Sciences Journal 60(4), 636-650.

636 Akan, A.O. and Houghtalen, R.J. (2003) Urban hydrology, hydraulics, and stormwater 637 quality: engineering applications and computer modeling, John Wiley \& Sons, Hoboken, NJ.

638 Alves, A., Sanchez, A., Vojinovic, Z., Seyoum, S., Babel, M. and Brdjanovic, D. (2016)

639 Evolutionary and Holistic Assessment of Green-Grey Infrastructure for CSO Reduction.

640 Water 8(9), 402-417.

641 Andrés-Doménech, I., Montanari, A. and Marco, J. (2011) Efficiency of storm detention tanks

642 for urban drainage systems under climate variability. Journal of Water Resources Planning 643 and Management 138(1), 36-46. 
644 Andrés-Doménech, I., Múnera, J., Francés, F. and Marco, J. (2010) Coupling urban event-

645 based and catchment continuous modelling for combined sewer overflow river impact

646 assessment. Hydrology and Earth System Sciences 14(10), 2057-2072.

647 Autixier, L., Mailhot, A., Bolduc, S., Madoux-Humery, A.S., Galarneau, M., Prevost, M. and

648 Dorner, S. (2014) Evaluating rain gardens as a method to reduce the impact of sewer

649 overflows in sources of drinking water. Sci Total Environ 499, 238-247.

650 Baek, H., Ryu, J., Oh, J. and Kim, T.-H. (2015) Optimal design of multi-storage network for

651 combined sewer overflow management using a diversity-guided, cyclic-networking particle

652 swarm optimizer - A case study in the Gunja subcatchment area, Korea. Expert Systems with

653 Applications 42(20), 6966-6975.

654 Calabrò, P.S. (2004) Design storms and water quality control. Journal of Hydrologic

655 Engineering 9(1), 28-34.

656 CCME (2009) Canada-wide strategy for the management of municipal wastewater effluent,

657 Canadian Council of Ministers of the Environment, Whitehorse, YT, Canada.

658 Chaosakul, T., Koottatep, T. and Irvine, K. (2013) Low Impact Development Modeling to

659 Assess Localized Flood Reduction in Thailand. Journal of Water Management Modeling.

660 CHI (2016) PCSWMM Version 6.2070, Computational Hydraulic International Toronto,

661 Ontario.

662 Cliche, G. and Saladzius, A. (2018) Évaluation de performance des ouvrages municipaux

663 d'assainissement des eaux - Bassin versant du lac à la Truite d'Irlande années 2014 à 2016 (in

664 French). Fondation Rivières.

665 DGALN-CEREMA (2014) Conditions pluviométriques locales, Direction générale de

666 l'Aménagement,du Logement et de la Nature, Centre d'études et d'expertise sur les risques,

667 l'environnement, la mobilité et l'aménagement. 
668 Dirckx, G., Korving, H., Bessembinder, J. and Weemaes, M. (2017) How climate proof is

669 real-time control with regard to combined sewer overflows? Urban Water Journal, 1-8.

670 Dirckx, G., Schütze, M., Kroll, S., Thoeye, C., De Gueldre, G. and Van De Steene, B. (2011)

671 Cost-efficiency of rtc for cso impact mitigation. Urban Water Journal 8(6), 367-377.

672 Dong, X., Guo, H. and Zeng, S. (2017) Enhancing future resilience in urban drainage system:

673 Green versus grey infrastructure. Water Res 124, 280-289.

674 Dunkerley, D. (2008) Identifying individual rain events from pluviograph records: a review

675 with analysis of data from an Australian dryland site. Hydrological Processes 22(26), 5024-

6765036.

677 Fontanazza, C., Freni, G., La Loggia, G. and Notaro, V. (2011) Uncertainty evaluation of

678 design rainfall for urban flood risk analysis. Water Science and Technology 63(11), 2641-

6792650.

680 Fortier, C. and Mailhot, A. (2014) Climate change impact on combined sewer overflows.

681 Journal of Water Resources Planning and Management 141(5), 04014073.

682 Fu, G. and Butler, D. (2014) Copula-based frequency analysis of overflow and flooding in 683 urban drainage systems. Journal of Hydrology 510, 49-58.

684 Fuamba, M., Walliser, T., Daynou, M., Rousselle, J. and Rivard, G. (2010) Vers une gestion

685 durable et intégrée des eaux pluviales : Une étude de cas pour le Québec. Canadian Journal of 686 Civil Engineering 37(2), 224-235.

687 Gooré Bi, E., Monette, F. and Gasperi, J. (2015a) Analysis of the influence of rainfall

688 variables on urban effluents concentrations and fluxes in wet weather. Journal of Hydrology

$689523,320-332$.

690 Gooré Bi, E.G., Monette, F., Gachon, P., Gasperi, J. and Perrodin, Y. (2015b) Quantitative

691 and qualitative assessment of the impact of climate change on a combined sewer overflow and

692 its receiving water body. Environ Sci Pollut Res Int 22(15), 11905-11921. 
693 Guo, Y. (2001) Hydrologic design of urban flood control detention ponds. Journal of

694 Hydrologic Engineering 6(6), 472-479.

695 Hvitved-Jacobsen, T. and Yousef, Y.A. (1988) Analysis of rainfall series in the design of

696 urban drainage control systems. Water Res 22(4), 491-496.

697 James, W. (2003) Rules for Responsible Modeling, CHI Guelph, Canada.

698 Jolliffe, I.T. and Stephenson, D.B. (2012) Forecast Verification: A Practitioner's Guide in

699 Atmospheric Science. Second Edition, W.S. (ed), pp. 33-34, Chichester, U.K. .

700 Keifer, C.J. and Chu, H.H. (1957) Synthetic storm pattern for drainage design. Journal of the

701 hydraulics division 83(4), 1-25.

702 Lucas, W.C. and Sample, D.J. (2015) Reducing combined sewer overflows by using outlet

703 controls for Green Stormwater Infrastructure: Case study in Richmond, Virginia. Journal of

704 Hydrology 520, 473-488.

705 Madoux-Humery, A.S., Dorner, S.M., Sauve, S., Aboulfadl, K., Galarneau, M., Servais, P.

706 and Prevost, M. (2015) Temporal analysis of E. coli, TSS and wastewater micropollutant

707 loads from combined sewer overflows: implications for management. Environ Sci Process

708 Impacts 17(5), 965-974.

709 Mailhot, A., Bolduc, S., Talbot, G. and Khedhaouiria, D. (2014) Gestion des eaux pluviales et

710 changements climatiques: Version finale, INRS, Centre Eau Terre Environnement.

711 Mailhot, A., Talbot, G. and Lavallée, B. (2015) Relationships between rainfall and Combined

712 Sewer Overflow (CSO) occurrences. Journal of Hydrology 523, 602-609.

713 Marcoux, C., Bacon, S., Beaumont, G., Fortier, V., Laverdière, M., Nantel, È., Pugin, S. and

714 Tremblay, K. (2011) Ville de Thetford Mines. Mise aux Normes des Ouvrages

715 d'Assainissement, Phase I de l'Ingénierie Préliminaire. Rapport Final. , p. 368, BPR, Québec,

716 Canada 
717 MDDELCC (2014) Position sur l'application des normes pancanadiennes de débordement des

718 réseaux d'égout municipaux, Ministère du Développement Durable de l'Environnement et de

719 la Lutte contre les Changements Climatiques, <http://www.mddelcc.gouv.qc.ca/eau/eaux-

720 usees/ouvrages-municipaux/position-ministere.htm> (Consulted 20.04.18)

721 MDDELCC (2017) Guide d'interprétation - Statistiques intensité-durée-fréquence (IDF) des

722 pluies de grandes récurrences - 1981-2010, Ministère du Développement Durable de

723 l'Environnement et de la Lutte contre les Changements Climatiques, Gouvernement du

724 Québec, Québec, Canada.

725 Montalto, F., Behr, C., Alfredo, K., Wolf, M., Arye, M. and Walsh, M. (2007) Rapid

726 assessment of the cost-effectiveness of low impact development for CSO control. Landscape

727 and Urban Planning 82(3), 117-131.

728 Müller, T., Schütze, M. and Bárdossy, A. (2017) Temporal asymmetry in precipitation time

729 series and its influence on flow simulations in combined sewer systems. Advances in Water

730 Resources 107, 56-64.

731 Nasrin, T., Sharma, A.K. and Muttil, N. (2017) Impact of short duration intense rainfall

732 events on sanitary sewer network performance. Water 9(3), 225.

733 Nie, L., Lindholm, O., Lindholm, G. and Syversen, E. (2009) Impacts of climate change on

734 urban drainage systems - a case study in Fredrikstad, Norway. Urban Water Journal 6(4), $735 \quad 323-332$.

736 Nilsen, V., Lier, J.A., Bjerkholt, J.T. and Lindholm, O.G. (2011) Analysing urban floods and

737 combined sewer overflows in a changing climate. Journal of Water and Climate Change 2(4),

$738 \quad 260-271$.

739 Passerat, J., Ouattara, N.K., Mouchel, J.-M., Rocher, V. and Servais, P. (2011) Impact of an

740 intense combined sewer overflow event on the microbiological water quality of the Seine

741 River. Water Res 45(2), 893-903. 
742 Powell, D.N., Khan, A.A., Aziz, N.M. and Raiford, J.P. (2007) Dimensionless rainfall

743 patterns for South Carolina. Journal of Hydrologic Engineering 12(1), 130-133.

744 Rivard, G. (2005) Gestion des eaux pluviales en milieu urbain: concepts et applications,

745 second Ed (in French). Alias communication design Inc., Québec, Canada, 329 p.

746 Rossman, L. and Huber, W. (2016) Storm Water Management Model Reference Manual

747 Volume I, Hydrology. US EPA Office of Research and Development (ed), Washington, DC.

748 Rousselle, J., Watt, W., Lathem, K., Neill, C. and Richards, T. (1990) Hydrologie des crues

749 au Canada: Guide de planification et de conception (in French). Conseil National de

750 Recherches Canada, Ottawa, 227.

751 Ruan, M. (1999) Continuous simulation of CSO emissions. Urban Water 1(3), 201-205.

752 Sandoval, S., Torres, A., Pawlowsky-Reusing, E., Riechel, M. and Caradot, N. (2013) The

753 evaluation of rainfall influence on combined sewer overflows characteristics: the Berlin case

754 study. Water Science and Technology 68(12), 2683-2690.

755 Schroeder, K., Riechel, M., Matzinger, A., Rouault, P., Sonnenberg, H., Pawlowsky-Reusing,

756 E. and Gnirss, R. (2011) Evaluation of effectiveness of combined sewer overflow control

757 measures by operational data. Water Science and Technology 63(2), 325-330.

758 Schütze, M., Willems, P. and Vaes, G. (2002) Global Solutions for Urban Drainage, pp. 1-11.

759 SCS (1968) Hydrology, Supplement A to Sec. 4, Engineering Handbook, Soil Conservation

760 Service Washington, DC.

761 Sebti, A., Fuamba, M. and Bennis, S. (2016) Optimization Model for BMP Selection and

762 Placement in a Combined Sewer. Journal of Water Resources Planning and Management $763 \quad 142(3), 04015068$.

764 Semadeni-Davies, A., Hernebring, C., Svensson, G. and Gustafsson, L.-G. (2008) The

765 impacts of climate change and urbanisation on drainage in Helsingborg, Sweden: Combined

766 sewer system. Journal of Hydrology 350(1-2), 100-113. 
767 Shoemaker, L., Riverson, J., Alvi, K., Zhen, J.X. and Murphy, R. (2011) Report on Enhanced

768 Framework (SUSTAIN) and Field Applications to Placement of BMPs in Urban Watersheds.

769 U.S. Environmental Protection Agency, Washington, DC.

770 Tavakol-Davani, H. (2016) Watershed-scale life cycle assessment of rainwater harvesting

771 systems to control combined sewer overflows, The University of Utah.

772 Thorndahl, S. and Willems, P. (2008) Probabilistic modelling of overflow, surcharge and

773 flooding in urban drainage using the first-order reliability method and parameterization of

774 local rain series. Water Res 42(1-2), 455-466.

775 USEPA (1993) Manual Combined Sewer Overflow Control, U.S. Environmental Protection 776 Agency, Cincinnati, $\mathrm{OH}$.

777 Vaes, G., Clemens, F., Willems, P. and Berlamont, J. (2002) Design Rainfall for Combined

778 Sewer System Calculations: Comparison between Flanders and the Netherlands. Global

779 Solutions for Urban Drainage, pp. 1-16.

780 Vaes, G., Willems, P. and Berlamont, J. (2001) Rainfall input requirements for hydrological

781 calculations. Urban Water 3(1-2), 107-112.

782 Verwom, H.-R. and Stuecken, L. (2001) The effects of uniform versus distributed rainfall

783 input on urban drainage modelling results. Engineers, A.S.o.C. (ed), pp. 30-40, Orlando,

784 Florida, USA.

785 Villarreal, E.L., Semadeni-Davies, A. and Bengtsson, L. (2004) Inner city stormwater control

786 using a combination of best management practices. Ecological Engineering 22(4-5), 279-298.

787 Watt, E. and Marsalek, J. (2013) Critical review of the evolution of the design storm event

788 concept. Canadian Journal of Civil Engineering 40(2), 105-113.

789 Willems, P. (2011) Revision of urban drainage design rules based on extrapolation of design

790 rainfall statistics. 
791 Yazdanfar, Z. and Sharma, A. (2015) Urban drainage system planning and design-challenges

792 with climate change and urbanization: a review. Water Science and Technology 72(2), 165-

793179.

794 Yen, B.C. and Chow, V.T. (1980) Design hyetographs for small drainage structures. Journal

795 of the Hydraulics Division 106(ASCE 15452).

796 Yen, B.C. and Chow, V.T., 1980. Design hyetographs for small drainage structures. Journal

797 of the Hydraulics Division, 106(ASCE 15452).

798 Yu, Y., Kojima, K., An, K. and Furumai, H. (2013) Cluster analysis for characterization of

799 rainfalls and CSO behaviours in an urban drainage area of Tokyo. Water Science and

800 Technology 68(3), 544-551. 


\section{HIGHLIGHTS}

1. Available types of rainfall input for CSO modelling were reviewed

2. CSO volume thresholds from continuous, historical and IDF-derived storms were compared

3. Continuous simulation is advisable for sizing solutions to limit CSO frequency

4. Single-rainfall events should be restricted to preliminary design

5. Design of CSO solutions is highly sensitive to the number of years simulated 

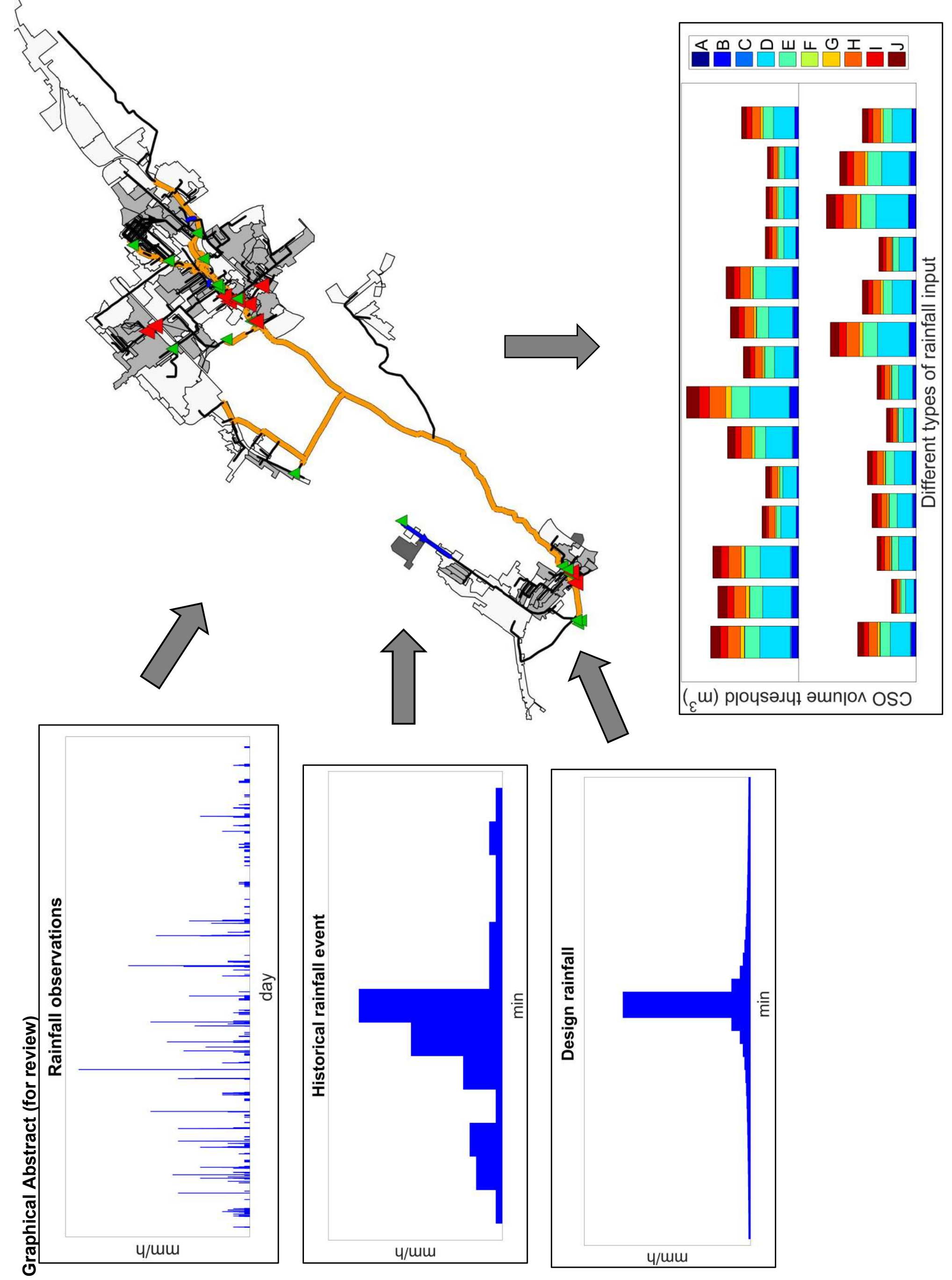


\section{FIGURE CAPTIONS}

Fig. 1. Combined sewer network and selected CSO structures

Fig. 2. Mean of correctly simulated CSO events for selected overflow structures and the WWTP. Note: The error bars show the annual maximum and minimum percentage of correct estimations. The dashed line shows the average annual proportion of correct estimations for the 10 selected overflow structures.

Fig. 3. Sensitivity to the number of years simulated of the total CSO volume thresholds estimated for the ten outfall structures

Fig. 4. Comparison of rainfall data selection methods for determining CSO volume thresholds from simulation

Fig. 5. Total CSO volume thresholds for the ten outfall structures based on the annual 7th greatest rainstorms in terms of total rainfall depth and MIT $=3,6,12$, and $24 \mathrm{~h}$

Fig. 6. CSO volume thresholds difference of all rainfall selection methods with quasicontinuous simulation per outfall structures. Note: The dashed lines show the limits for a volume difference of $\pm 25 \%$. 


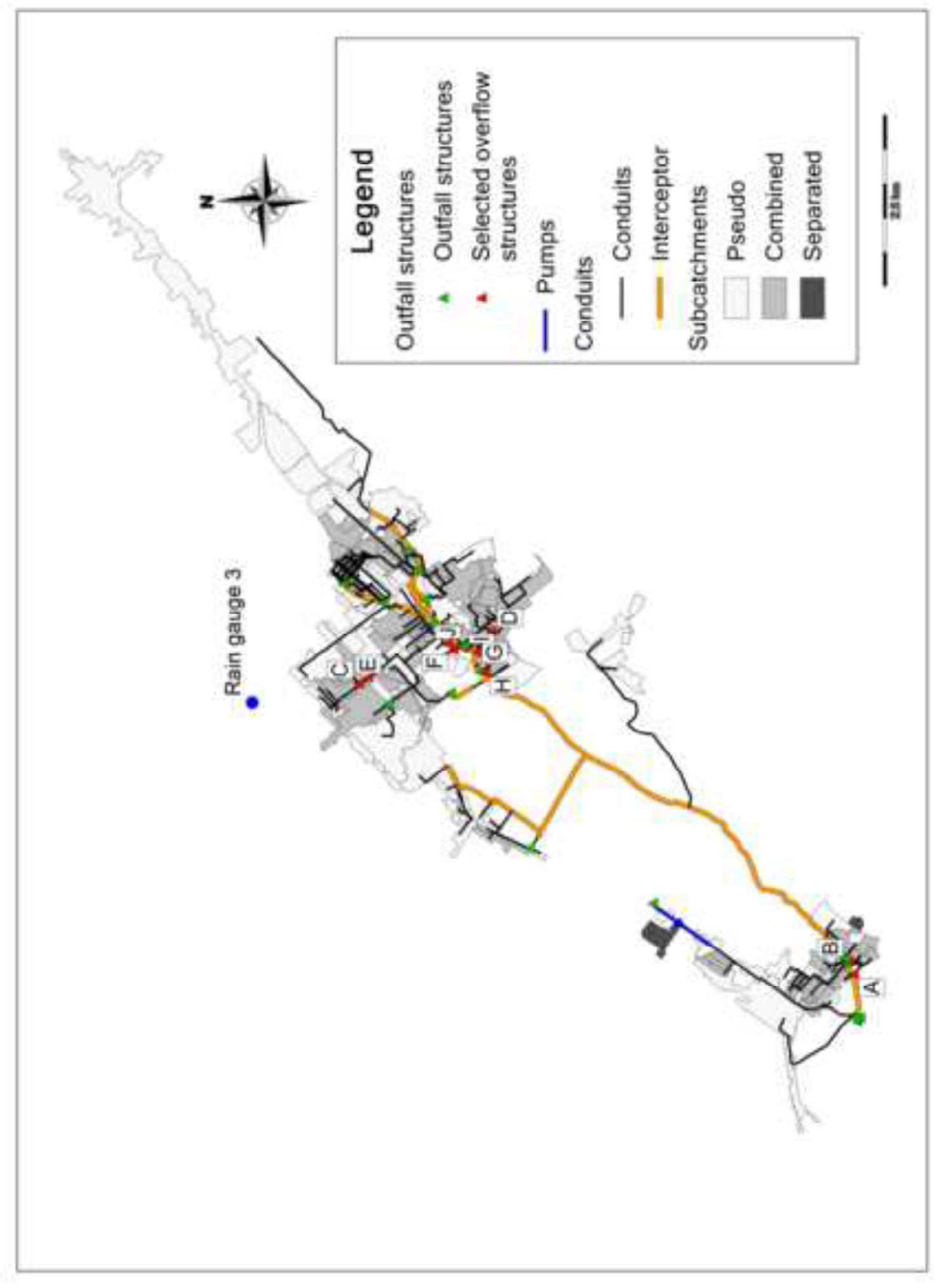




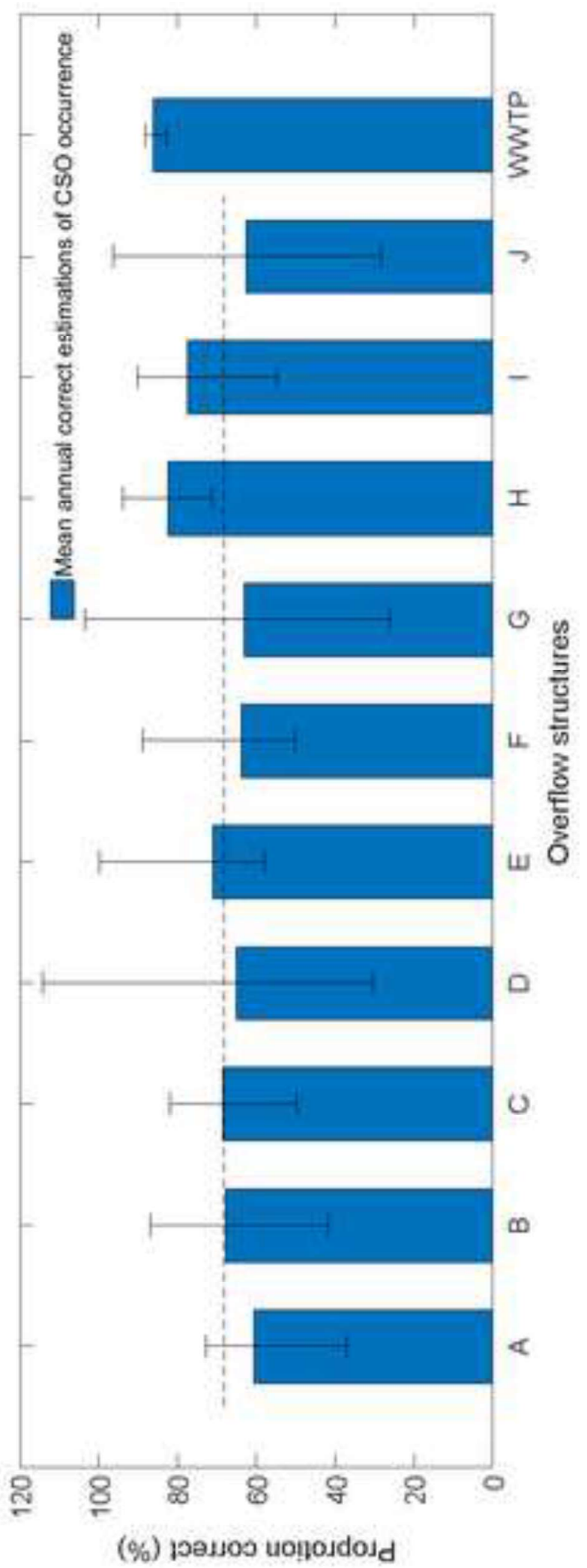




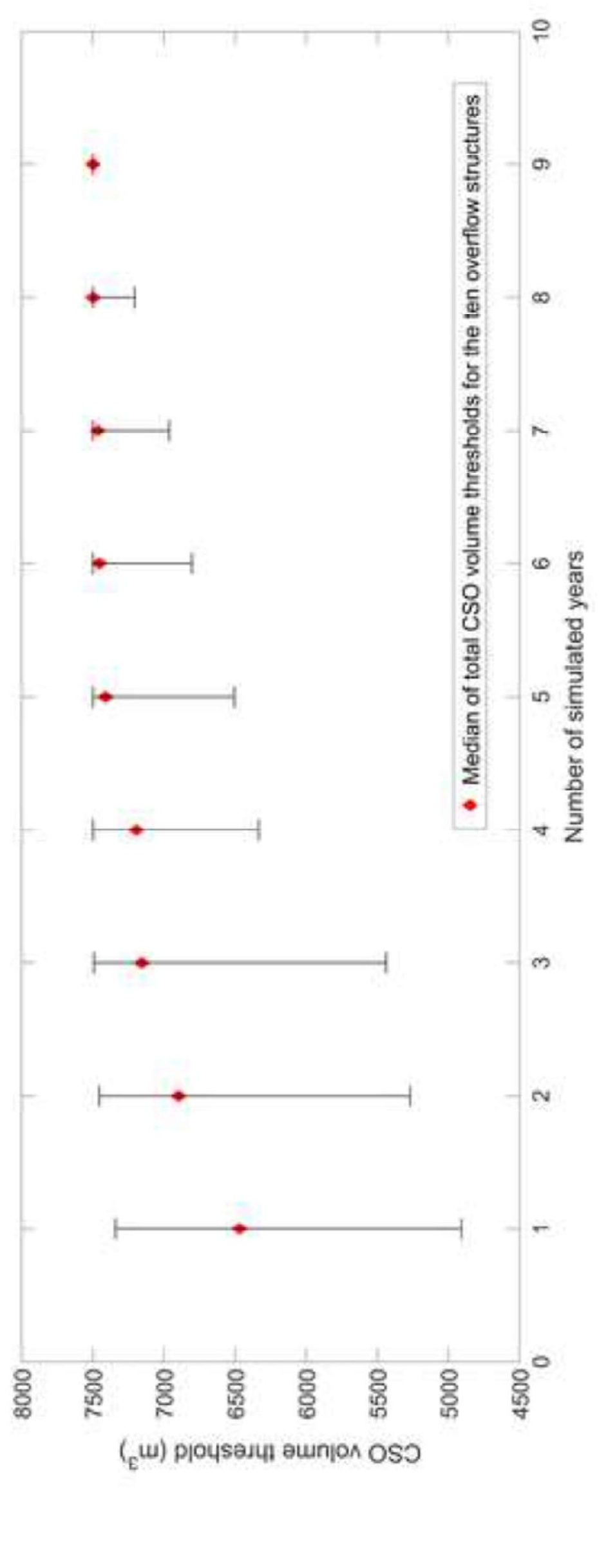



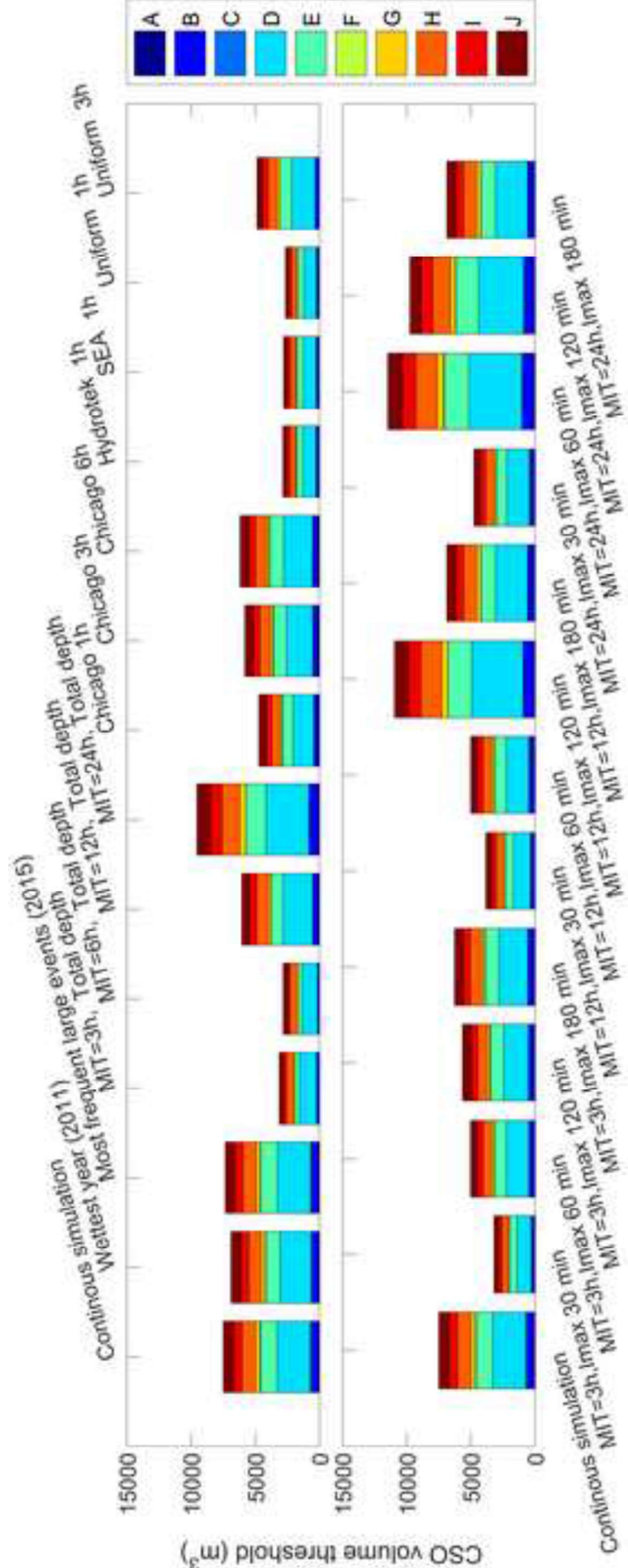

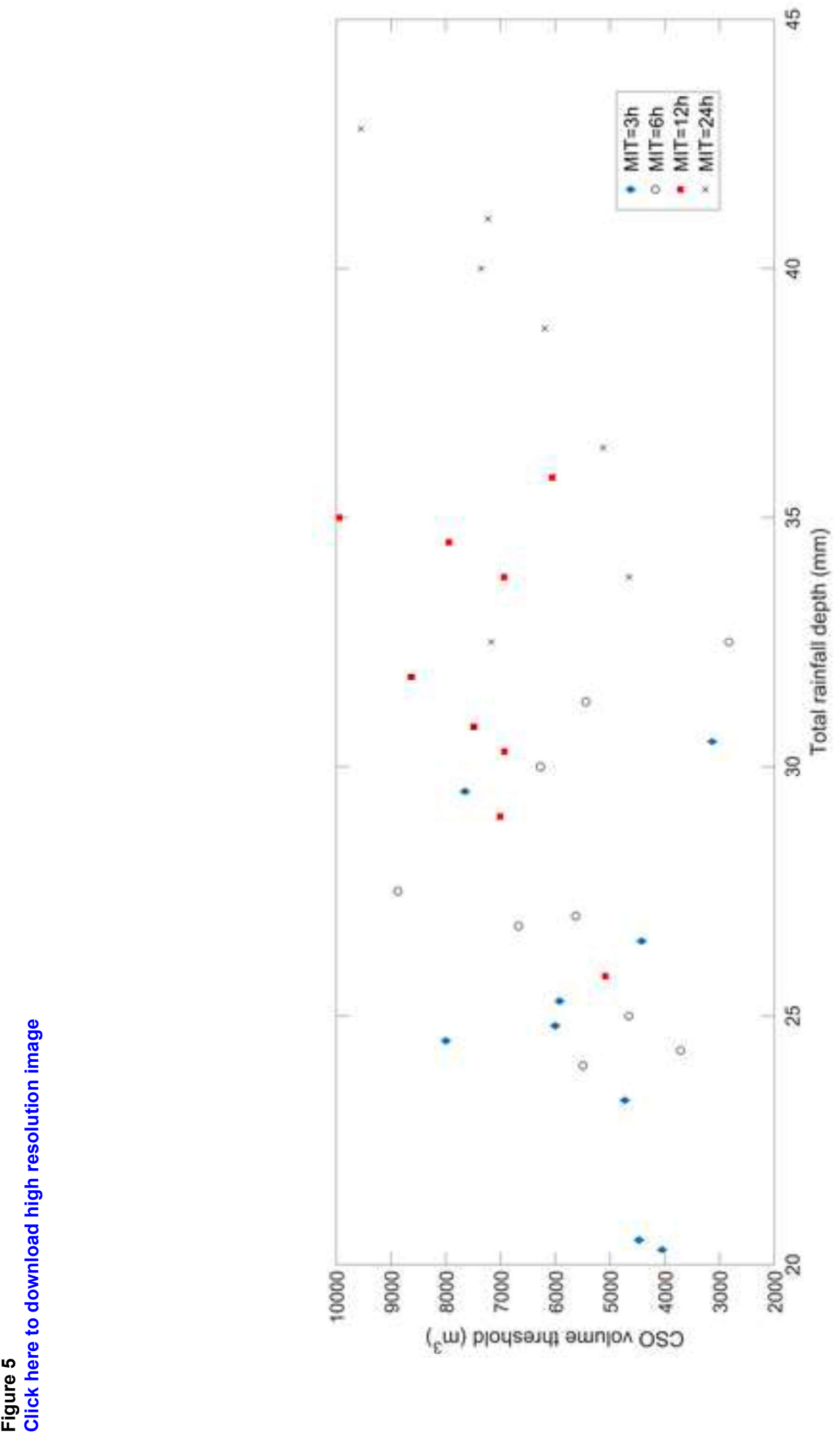

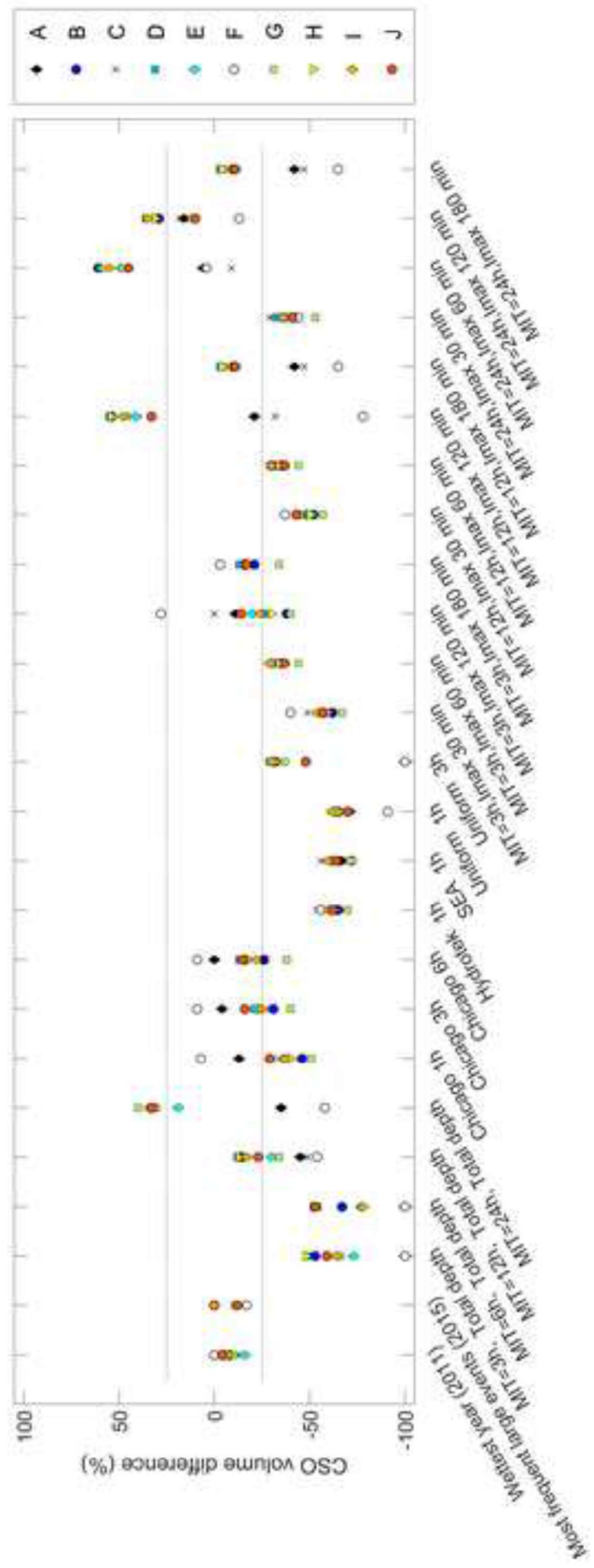